\title{
Author Correction: Opportunities and challenges for combining chemo- and biocatalysis
}

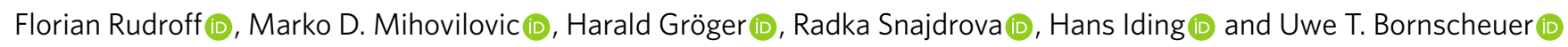
Correction to: Nature Catalysis https://doi.org/10.1038/s41929-017-0010-4, published online 8 January 2018.

In this Review Article originally published, the ORCID number for the author Radka Snajdrova was incorrect; it should have been 0000-0002-4809-1066. This has now been corrected in all versions of the Review Article. 